\title{
Outcome Assessment Using Connected Vehicle Data to Justify Signal Investments to Decision Makers
}

\author{
Drake Krohn \\ Purdue University \\ dkrohn@purdue.edu \\ Lou Rymarcsuk \\ Purdue University \\ lourym@purdue.edu \\ Jijo Mathew \\ Purdue University \\ kjijo@purdue.edu \\ Chris Day \\ Purdue University \\ cmday@purdue.edu \\ Howell Li \\ Purdue University \\ howell-li@purdue.edu \\ Ashwin Patel \\ Pennsylvania Department of Transportation \\ ashpatel@pa.gov \\ Daniel Farley \\ Pennsylvania Department of Transportation \\ dfarley@pa.gov \\ Darcy M. Bullock, Corresponding Author \\ Purdue University \\ 207 S. Martin Jischke Drive, West Lafayette, IN 47907 \\ (765) 496-2226 \\ darcy@purdue.edu
}




\begin{abstract}
Elected officials and decision makers are increasingly seeking outcome assessment of capital projects, such as corridor signal modernization and adaptive control projects. This paper describes the use of connected vehicle data to perform corridor travel time outcome assessment along five corridors in the greater Philadelphia, Pennsylvania area. These corridors are comprised of a total of 2,184 signals and are considered five of the most critical corridors in this region, experiencing a high volume of traffic, with AADT greater than 30,000 vehicles. These corridors were evaluated for six weeks before and after the adaptive installation through the use of private-sector segment speed data. Medians and interquartile ranges of travel times were used to assess the impact on arterial progression. Various graphs, charts, and figures produced through web tools and traditional metrics provide a user-interactive component to the dashboards. In addition, user cost reductions and $\mathrm{CO}_{2}$ emission impacts were also determined. Four out of the five corridors had substantial reductions of arterial travel times that amounted to approximately $\$ 36.6$ million in annualized user benefits.

The paper concludes by recommending these techniques be integrated into modern traffic signal central systems to prioritize timing initiatives to perform outcome assessment. Such tools would complement high resolution traffic signal data performance measures that identify minor side street split failures to provide agencies with a complete set of tools for managing their signal system infrastructure.
\end{abstract}




\section{BACKGROUND}

A central concept of system engineering is to define the goals and objectives of the system, then measure the outcomes of the system performance to determine whether those goals and objectives are being adequately met. In the operation of coordinated traffic signal systems, these are determined by the operating environment of the system and the needs of the stakeholders.

Corridor progression is a common objective of traffic signal system operations, particularly for arterial highways. Travel time is perhaps the most common performance measure used to evaluate the quality of progression. This can be measured by a number of techniques, such as GPS travel time runs (1) or vehicle re-identification $(2,3)$, and estimated by the analysis of segment speed data sampled from connected vehicles from private-sector data providers $(4,5,6,7)$. Several researchers have recently explored the viability of private sector speed data for analysis of arterial travel times $(4,5,6)$. While results have varied, the growing consensus is that such data is viable on corridors with higher traffic volumes. A recent study demonstrated the scalability of this data set by applying the method to a large inventory of corridors on a statewide level, ranking them by travel time and travel time reliability metrics for multiple times of day (7).

Adaptive signal control is one application where such analysis tools are essential to evaluate the return on investment. In 2013, the University of California, Berkley evaluated adaptive signals based on field data collected through Bluetooth detectors $(8)$. For this particular corridor, the implementation of adaptive signals had a detrimental effect, which was attributed to suboptimal splits and offsets for specific intersections. A recent study by the Virginia Department of Transportation (9) explored six adaptive control deployments and observed reductions in travel time averaging about $25 \%$, with a $16 \%$ improvement in travel time reliability, using private-sector speed data spatially segmented using the Traffic Message Channel (TMC) scheme.

There is clear consensus that outcome assessment is an important part of any traffic signal modernization or adaptive control project. However, all of these techniques used in past studies are quite labor intensive. To address the need for an assessment tool, the Pennsylvania Department of Transportation (PennDOT) initiated a project to adapt the corridor ranking tool (7) to a district-wide level web tool incorporating 138 corridors. That ranking methodology was further extended to visualize before and after effects in terms of both travel time and travel time reliability. Of these corridors, five recently incorporated adaptive deployments that varied from full-corridor to partial-corridor deployments, are evaluated. In this study, the more spatially detailed "XD" segmentation scheme is used. Results are examined for each hour of the day from 6:00 a.m. to 8:00 p.m. for all five corridors, and the annualized user benefits are calculated.

\section{STUDY LOCATION}

This study is part of a larger project sponsored by the Pennsylvania Department of Transportation (PennDOT), concentrating on analyzing and ranking high-volume signalized arterial corridors around the Philadelphia area. This region is defined as District 6 and consists of 5 counties: Bucks, Chester, Delaware, Montgomery, and Philadelphia. Within the district, there are 138 corridors, stretching along 766 miles, and totaling 2,184 signals. In the past few years, Pennsylvania has accelerated its investments in signal infrastructure with its "Green Light Go" program, which has led to a number of improvements, including several adaptive deployments (10).

Five corridors where adaptive signal control was deployed within the past 12 months were selected for before-and-after analysis. Table 1 provides a listing of these corridors and their characteristics. These five 
arterials account for over 180,000 vehicles per day total and are highlighted in Figure 1. The density of signals on these five corridors is roughly 3.3 signals per mile on average. Some of these corridors are particularly long and included a mixture of segments with conventional signal control as well as other segments with adaptive signal control. Altogether, 61 out of 186 signals had adaptive control installed on these five corridors during the study period (Figure 2).

This study analyzes the impact of these adaptive deployments on arterial travel times using minute-byminute representative speeds from connected vehicles along pre-defined roadway segments over the targeted date ranges defined in Table 1 . The before date range indicates the period prior to adaptive deployment, and the after period samples the effect of the deployment on the travel times. The speed limits of the segments were also tabulated for each segment to determine travel times in absence of congestion or controlled delay. The speed limits along the corridors varied between 25 and $55 \mathrm{mph}$ and are used to compute the baseline ideal travel time in the analysis.

Table 1. Corridor Information

\begin{tabular}{|c|c|c|c|c|c|c|c|}
\hline $\begin{array}{l}\text { Corridor } \\
\text { ID }\end{array}$ & Corridor Name & AADT & $\begin{array}{l}\text { Length } \\
\text { (mi) }\end{array}$ & $\begin{array}{l}\text { Average } \\
\text { Speed } \\
\text { Limit } \\
(\mathrm{mph})\end{array}$ & $\begin{array}{c}\text { Signal } \\
\text { Count } \\
\text { (Adaptive } \\
\text { Signals) }\end{array}$ & $\begin{array}{c}\text { Before Date } \\
\text { Range }\end{array}$ & $\begin{array}{l}\text { After Date } \\
\text { Range }\end{array}$ \\
\hline A1 & PA 132 / Street Rd & 33,965 & 15.2 & 45 & $50(21)$ & $\begin{array}{c}10 / 12 / 2015- \\
11 / 23 / 2015\end{array}$ & $\begin{array}{l}1 / 4 / 2016- \\
2 / 15 / 2016\end{array}$ \\
\hline $\mathrm{A} 2$ & $\begin{array}{c}\text { PA } 332 \text { (Newtown } \\
\text { Bypass) }\end{array}$ & 35,015 & 4.8 & 53 & $12(12)$ & $\begin{array}{c}2 / 22 / 2016 \\
4 / 4 / 2016\end{array}$ & $\begin{array}{c}4 / 25 / 2016 \\
6 / 6 / 2016\end{array}$ \\
\hline A3 & $\begin{array}{l}\text { US 1/State Rd/Township } \\
\text { Line } \mathrm{Rd} / \text { City Ave }\end{array}$ & 35,268 & 10.0 & 36 & $40(4)$ & $\begin{array}{c}10 / 12 / 2015- \\
11 / 23 / 2015\end{array}$ & $\begin{array}{l}3 / 7 / 2016- \\
4 / 18 / 2016\end{array}$ \\
\hline A4 & $\begin{array}{c}\text { US 202/Wilmington } \\
\text { Pkwy }\end{array}$ & 46,553 & 8.6 & 45 & $16(9)$ & $\begin{array}{c}9 / 4 / 2015- \\
10 / 26 / 2015\end{array}$ & $\begin{array}{l}1 / 4 / 2016- \\
2 / 15 / 2016\end{array}$ \\
\hline A5 & $\begin{array}{c}\text { PA 611/Old York Rd/ } \\
\text { Easton Rd }\end{array}$ & 30,919 & 16.3 & 42 & $68(15)$ & $\begin{array}{c}4 / 27 / 2015- \\
6 / 8 / 2015\end{array}$ & $\begin{array}{l}1 / 4 / 2016 \\
2 / 15 / 2016\end{array}$ \\
\hline
\end{tabular}




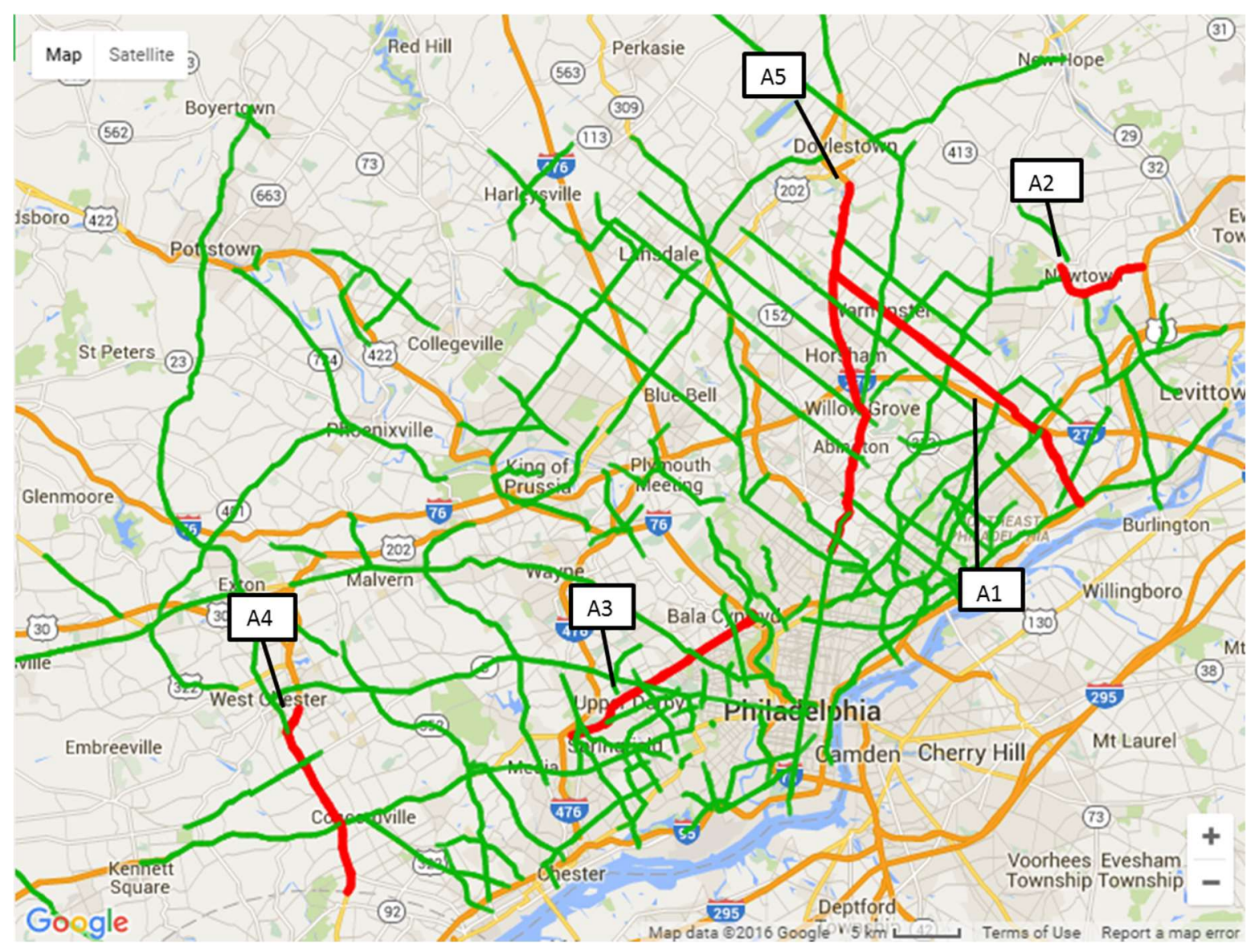

Figure 1. Selected Corridors in Greater Philadelphia Area 


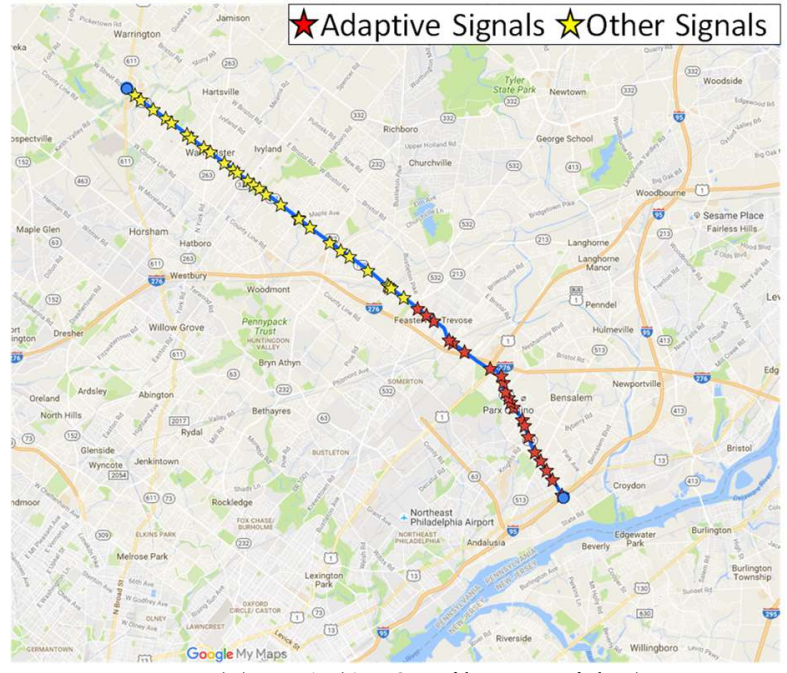

(a) A1 (15.2 miles corridor)

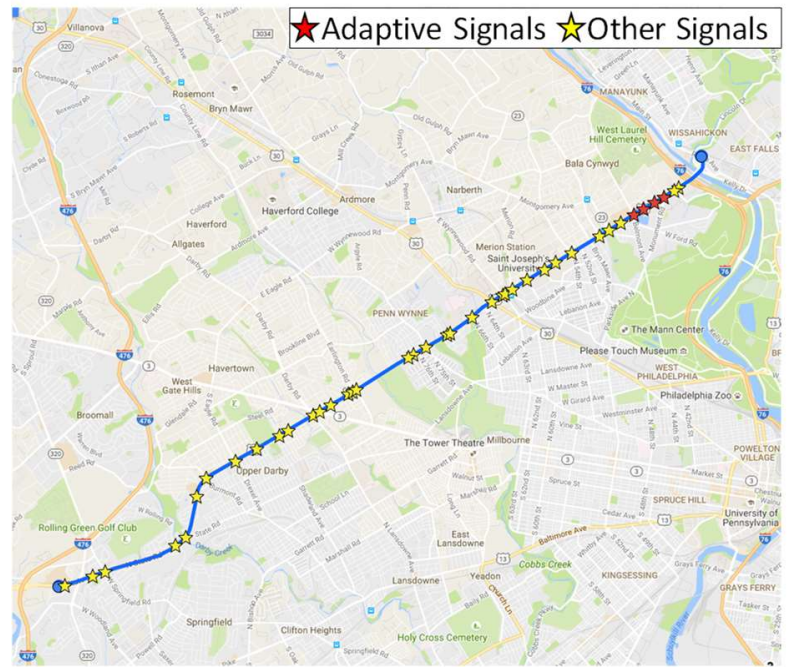

(c) A3 (10 miles corridor)

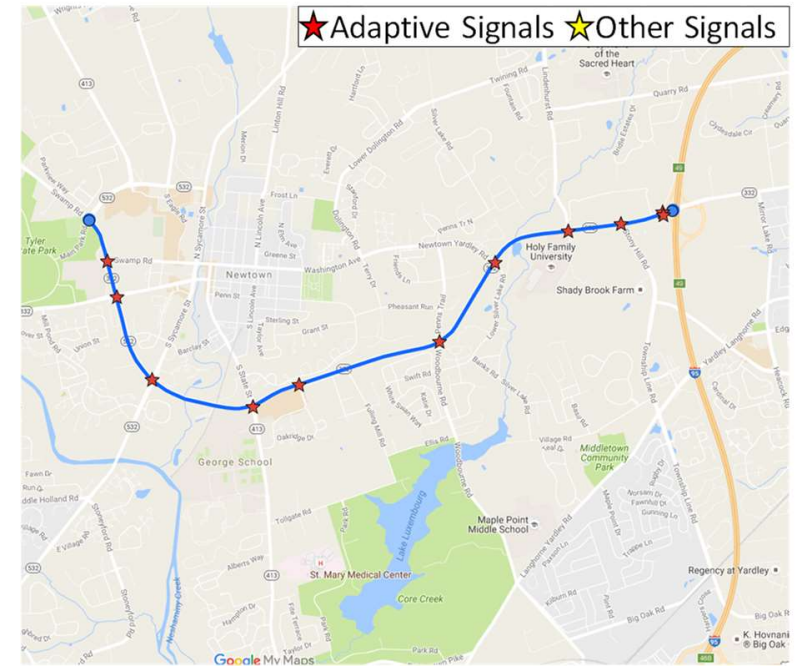

(b) A2 (4.8 miles corridor)

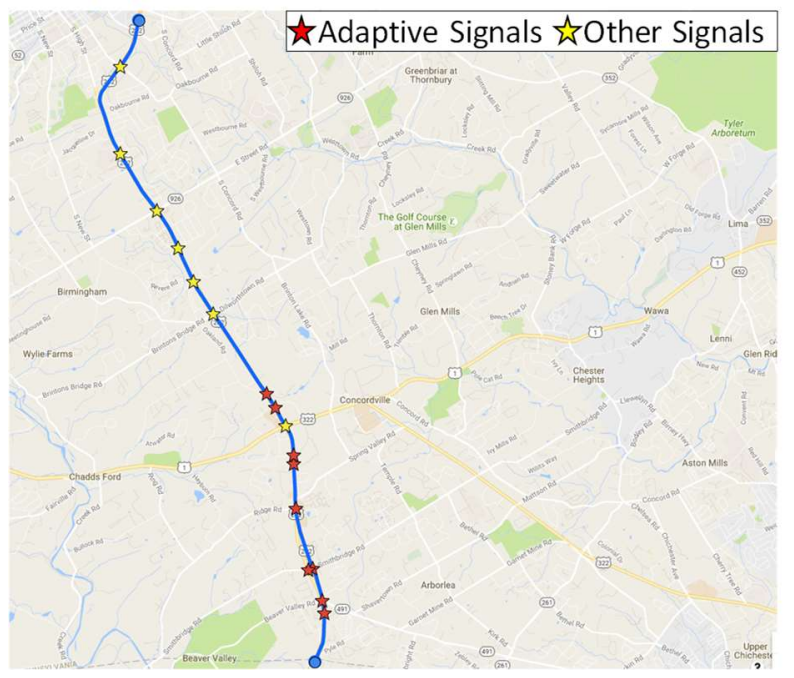

(d) A4 (8.6 miles corridor)

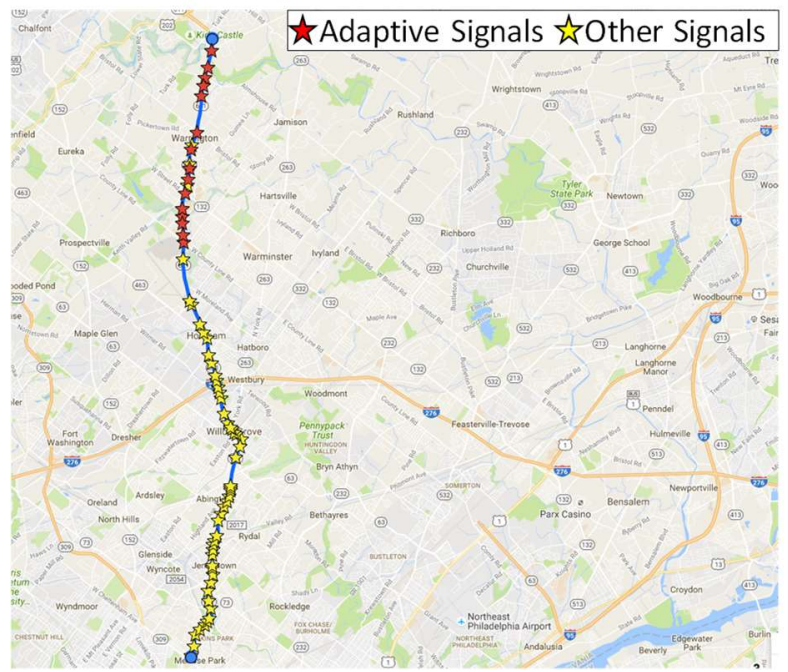

(e) A5 (16.3 miles corridor)

Figure 2. Corridor Maps of Intersections Running Adaptive Control 


\section{EVALUATION METHODOLOGY}

Travel times are evaluated using private-sector connected vehicle speeds. These speeds are obtained on a minute-by-minute basis from aggregation of individual vehicle speeds determined from timestamped positions of GPS-enabled devices, including fleet telematics and cellular phones. For this study, segment definitions from the data provider are used, each approximately 1 mile in length. The five arterials in this study included 186 total single-direction segments. Multiple samples for all minutes in a time-of-day period, aggregated across multiple days in a given date range, provides an estimated distribution of corridor travel times during that period.

\section{Travel Time Distributions for a Single Corridor}

Figure 4 illustrates two cumulative distribution functions (CDF) for corridor A3 comparing a six-week period in October/November 2015 (before adaptive control deployment) and another six-week period in March/April 2016 (after deployment), for the two directions of travel. The analysis period includes weekdays during the hours of 17:00 and 18:00 representative of the PM peak period, avoiding holidays and periods where winter weather was likely to affect the operation. The eastbound and westbound sections are composed of 21 and 22 travel time segments, respectively (Figure 3). The vertical dotted line in each figure represents the travel time in each direction at the speed limit without stops, while the red and green curves represent the observed distribution of estimated travel times over the before and after periods respectively, during the specified hours.

The CDFs in Figure 4a show an overall reduction in estimated travel times after adaptive control was deployed. For the $25^{\text {th }}$ percentile, median, and $75^{\text {th }}$ percentile, 3.5, 3.6, and 3.7 minutes of respective improvements are estimated in the eastbound direction. The travel times range from 22.8 to 46.9 minutes in the before period, compared to 21.0 to 38.9 in the after period, indicating that travel times were more reliable, with less variation and a slightly steeper curve. Figure $4 \mathrm{~b}$ shows an even more significant improvement in the westbound direction, with 3.6, 5.6, and 7.7 minute reductions for the $25^{\text {th }}$ percentile, median, and $75^{\text {th }}$ percentile respectively. The travel time ranges from 21.9 to 61.2 minutes in the before period, compared to 18.9 and 42.2 minutes in the after period, showing a substantial improvement in reliability. 


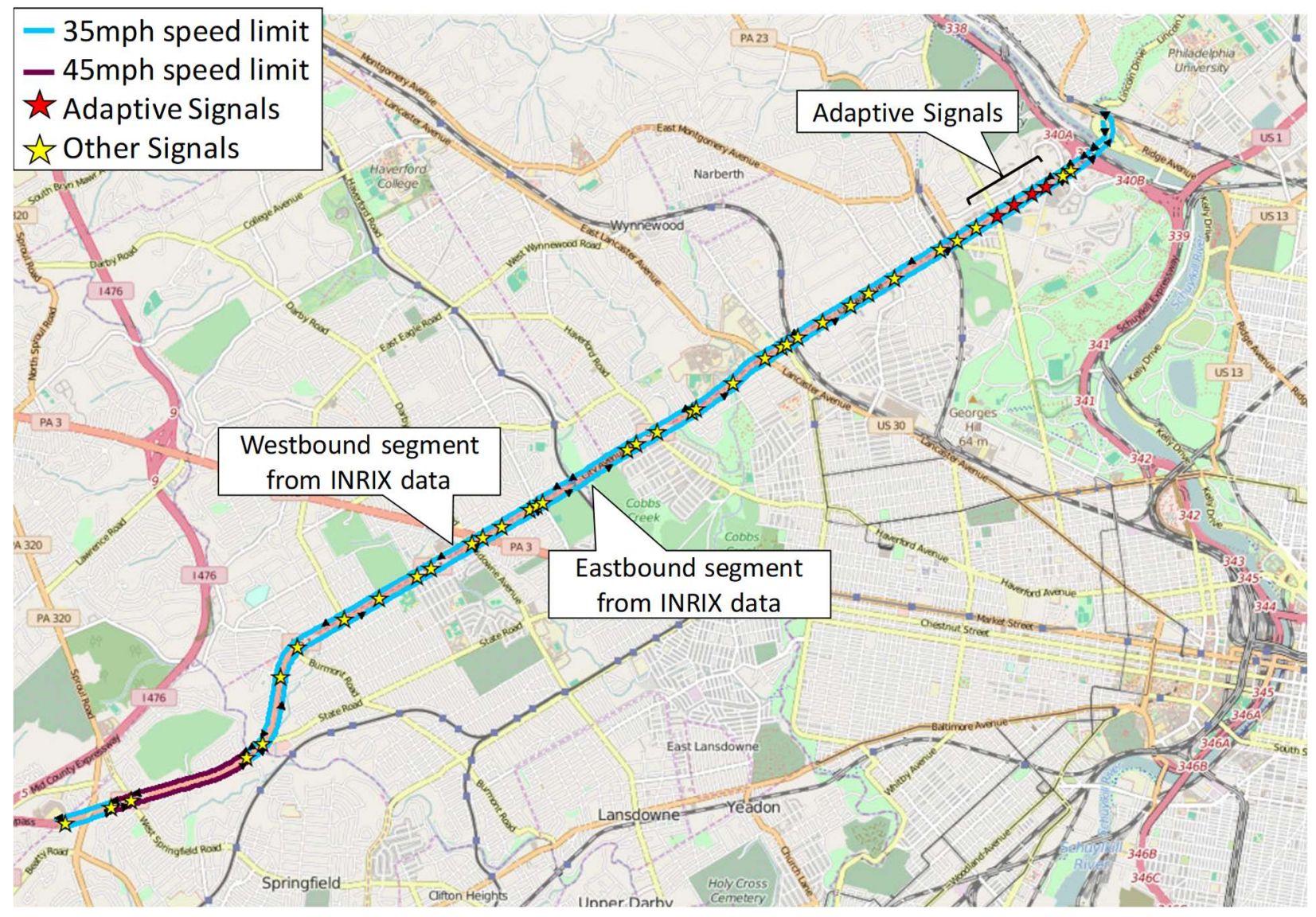

Figure 3. Corridor A3 


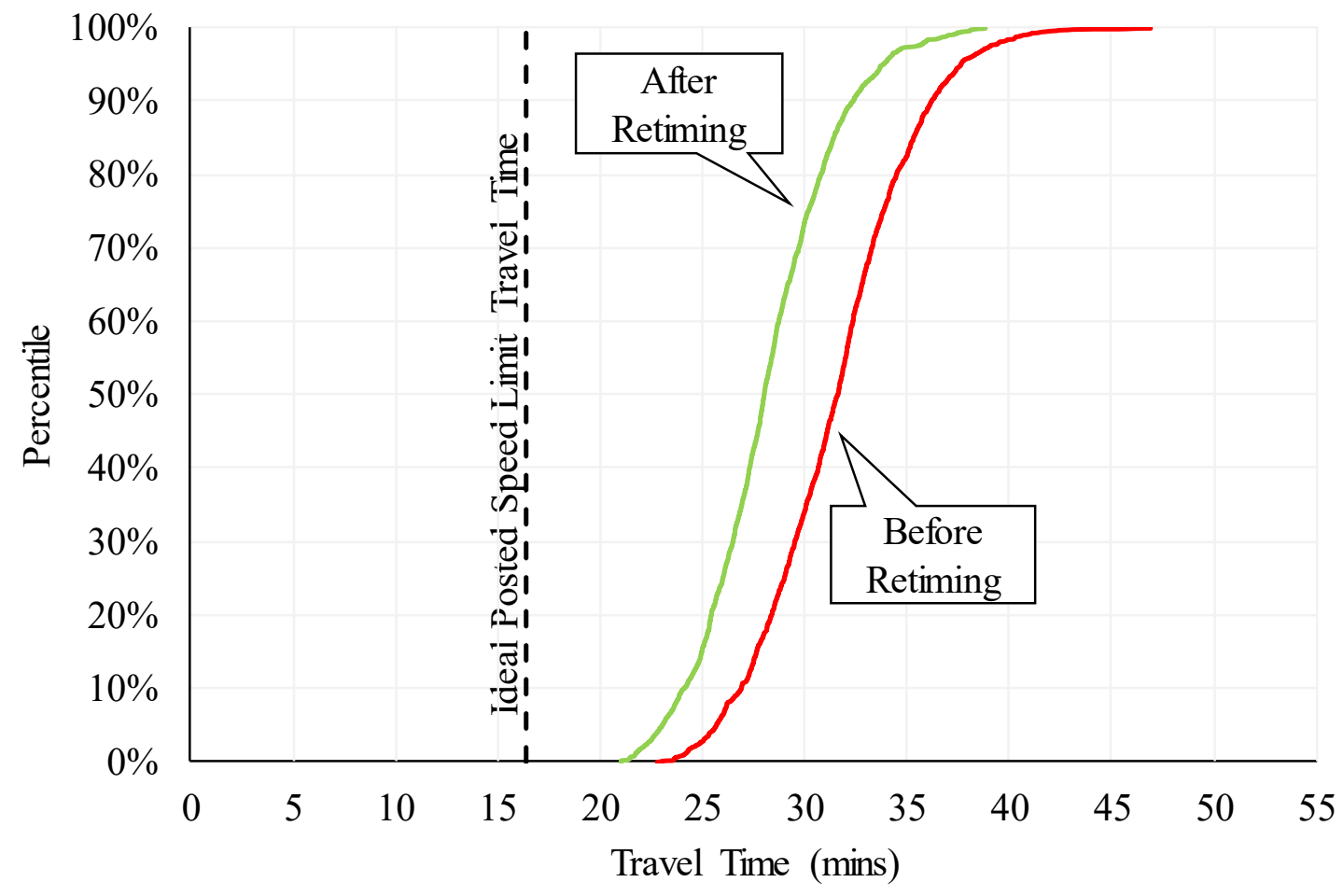

a) Eastbound

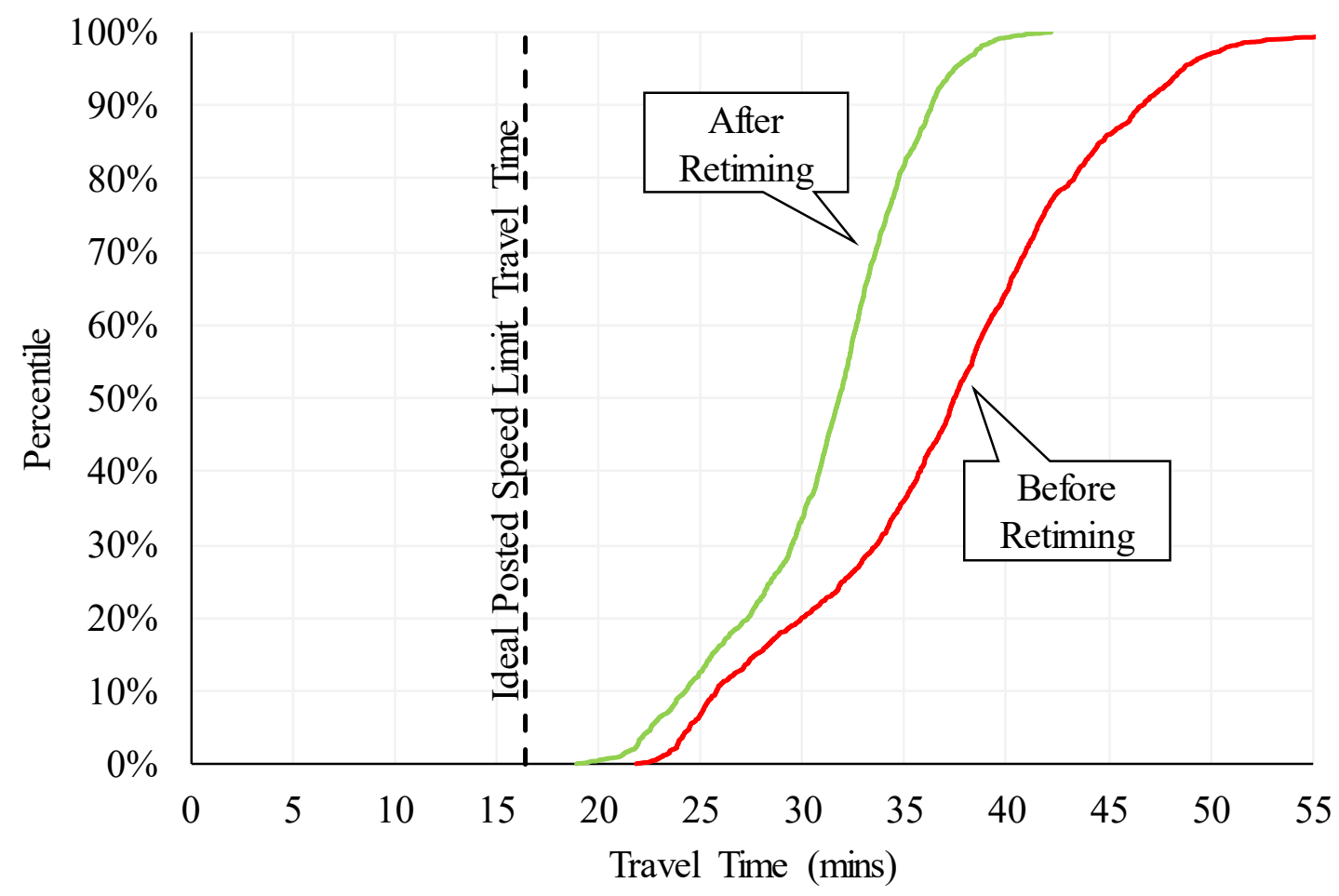

b) Westbound

Figure 4. Corridor A3, Weekdays, 17:00-18:00

Travel Times Before and After Installation of Adaptive Signal Control 


\section{Analysis of 138 Signalized Arterial Corridors}

Travel time comparisons are typically made by developing distributions of measured travel times and extracting metrics from percentiles of the distribution or other statistical properties (11). Although privatesector speed data does not directly provide individual vehicle travel time measurements, such measurements made over time yield a distribution that can give a sense of the central tendency of the travel time along a corridor, and its degree of variability (12). For this study, the median is selected to quantify the central tendency, while the interquartile range (IQR), the difference between the $75^{\text {th }}$ and $25^{\text {th }}$ percentiles, is used to quantify its variability.

Because the corridors are different lengths, their travel times need to be normalized to make their travel time values comparable. One way to do so is to divide the travel time by the route distance, which would state the travel time as a rate per unit distance. However, because the speed limits also vary by corridor, this would tend to make slower corridors appear relatively worse, whereas the lower speeds may reflect the intended operation at lower speed limits. Instead, the travel time metrics are divided by the ideal travel time, which is considered to be travel on each segment at its speed limit.

Figure 5 shows the normalized median and Inter Quartile Range (IQR) of travel time for each directional route along all 138 corridors as a point cloud (thus including 276 routes). The data is shown in October 2015 during the 17:00 to 18:00 hours for all weekdays using a similar visualization as previously published by Day et al (7). The x-axis shows the median travel time; any routes with a value at the $100 \%$ value would show median speeds exactly at the speed limit. All of the routes in the district have median travel times greater than ideal, or to the right of the $100 \%$ mark, although there are some routes where one direction is approaching $100 \%$. There are 43 routes with median travel times greater than $200 \%$ of the ideal time, indicating that their average speeds are less than half of the speed limit.

Along the $y$-axis, the normalized IQR is charted to show the reliability of each route. A normalized IQR of $0 \%$ would represent that all of the travel times between $25 \%$ and $75 \%$ were exactly the same; a normalized IQR of 50\% represents that this central range of the distribution is as wide as half of the entire route travel time itself. There are 9 routes that have normalized IQR above 50\%. Generally, routes plotted in the lower-left quadrant of the chart tend to experience faster and more reliable travel times, while those in the upper-right quadrant tend to experience slower and less reliable travel times, relative to the speed limit. It is not difficult to imagine that, over time, the position of a route would move around over time as their performance changed.

Figure 6 shows the before after change of both median travel time and IQR movement in one figure. This chart has identical axes and dimensions as Figure 5, but only includes the five corridors where adaptive systems were implemented (Table 1). For each directional route, distinct 6-week "before" and 6-week "after" periods were used to assess the changes in performance associated with the deployment of the adaptive systems. The performance of the "before" period is plotted as a dot, while the "after" period is plotted as a triangle. A line is drawn connecting the two periods associated with the same route. Routes that had decreases in both the median and IQR are colored green, while routes that had increases in both median and IQR degradation are colored red. Corridors with mixed results are colored orange. The corridor with the largest improvement from an adaptive implementation was westbound A3, which had a 34.2-percentage point decrease in the normalized median travel time and a 24.9-percentage point decrease in the normalized IQR travel time. This corresponds to the CDF that was shown earlier in Figure $4 \mathrm{~b}$. 


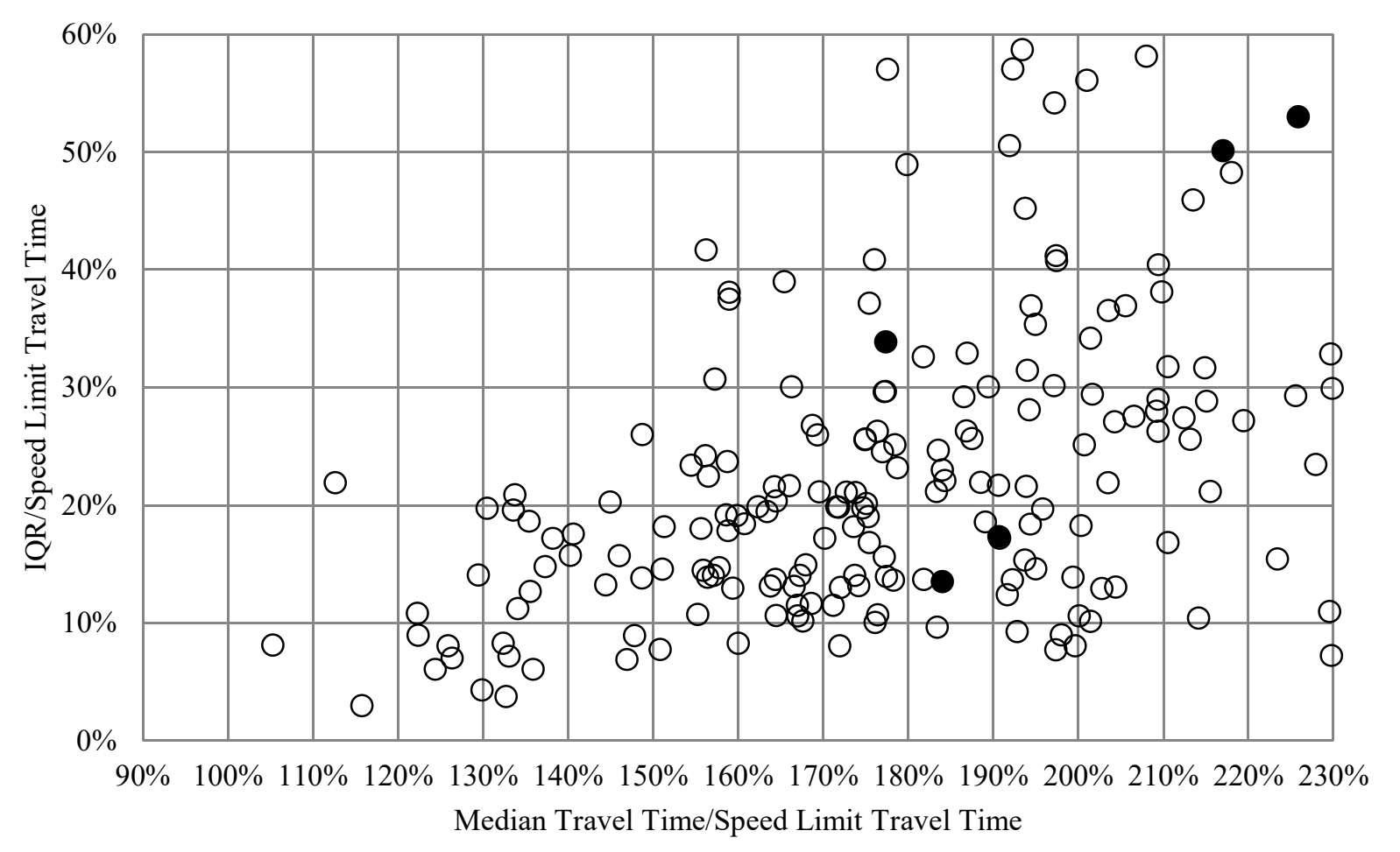

Figure 5. Speed and Reliability Sample for District 6 Corridors, Oct 2015, Weekdays, 17:00 to 18:00

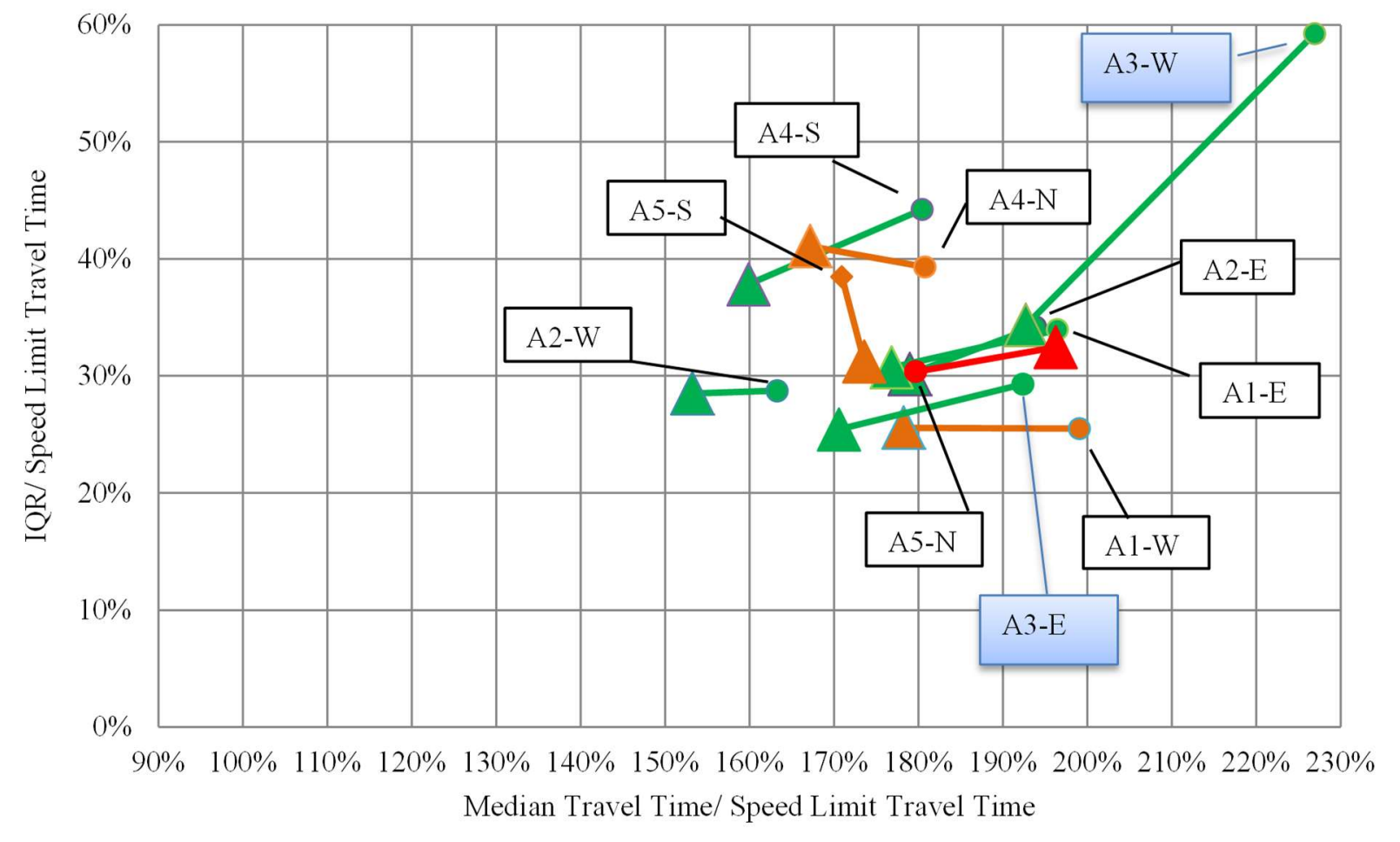

Figure 6. Travel Time and Reliability Trends for Adaptive Installations.

Data is shown for Weekdays, 17:00-18:00, for Before and After Periods Indicated in Table 1 


\section{Hour-by-Hour Median and IQR Evaluation}

To more completely characterize a corridor's change in travel performance, the changes in IQR are analyzed over an entire day during the AM (6:00 AM-10:00 AM), mid-day (10:00 AM to 4:00 PM), and PM peak (4:00 PM to 8:00 PM) hours. For this analysis, one-hour intervals are analyzed throughout the week, including weekends, for all time periods. The travel times before and after the adaptive implementation are evaluated based on median travel times and comparisons of IQR. Before and after evaluation periods are six weeks in length each for consistency and excluding any holidays or atypical travel days. Through these evaluation metrics, a comprehensive and quantitative analysis of the travel times can be conducted. Visual representations of improved travel times can be seen in Figure 7 and Figure 8.

Figure 7 shows that, in general, the greatest improvement in adaptive signals are made during weekday AM and PM peak periods. Most of the corridors also had improvements during the mid-day period, with corridor A1 seeing the most improvements. Corridor A2 had the least amount of improvement, however, the existing condition of the signals already had a consistently uniform distribution throughout the day, even during both rush hour periods. Corridor A3 appears to have had the biggest improvement during the weekday rush hours. In fact, for nearly every weekday hour, travel time decreased by $25 \%$. Corridor A 4 had an interesting outcome, as, throughout the corridor, the $25^{\text {th }}$-percentile travel time did not decrease. However, overall corridor performance increased with increased reliability through a reduction in the $75^{\text {th }}$-percentile travel time. The opposite is true for corridor A5 evening rush hour, which saw the greatest degradation of all the corridors. Similar increases in travel times were experienced during the morning rush hours in both directions.

Figure 8 shows that a majority of weekend improvements came in the afternoon and evening hours. The greatest improvements for weekend traffic can be seen in corridor A1 and southbound A4. As with the weekday travel times, weekends for corridor A2 were very consistent throughout the day. Corridor A3 appears to have the largest evening impact, with travel times increasing by ten minutes when comparing 1 PM to 4-5 PM. Corridor A5 continued to have reliability issues throughout the weekend period, especially for northbound evenings. 


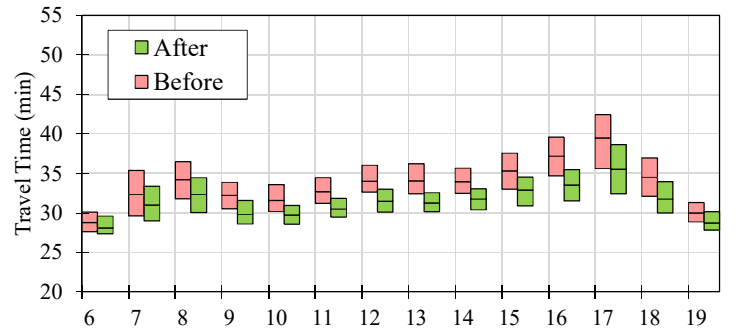

a) Corridor A1, Eastbound
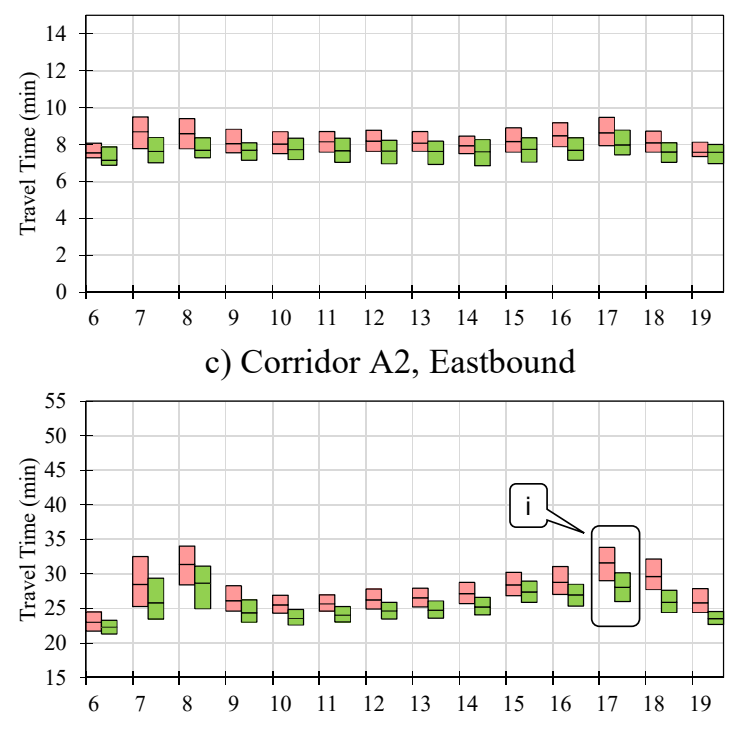

e) Corridor A3, Eastbound

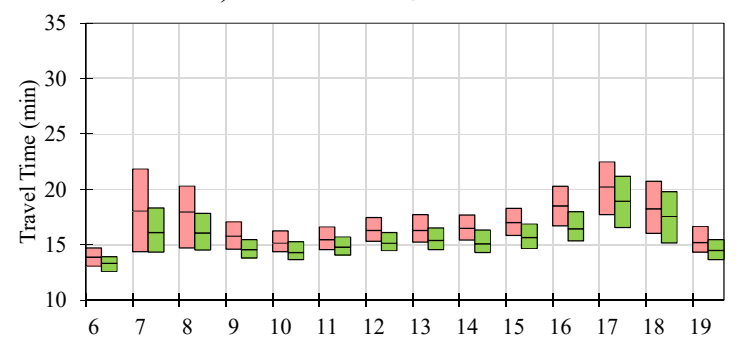

g) Corridor A4, Northbound

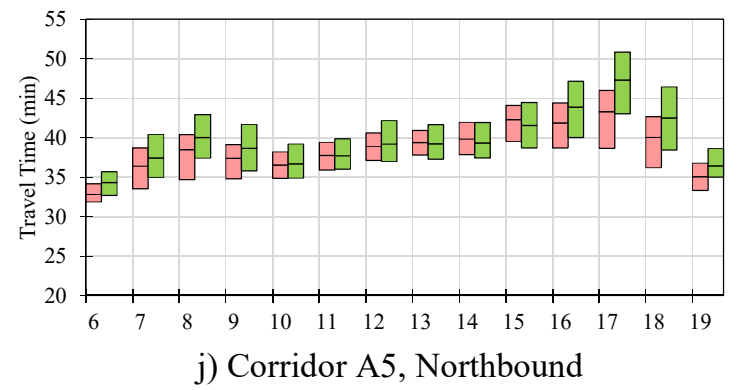

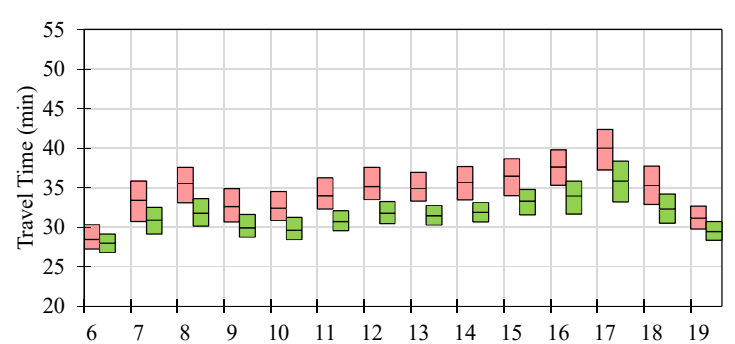

b) Corridor A1, Westbound

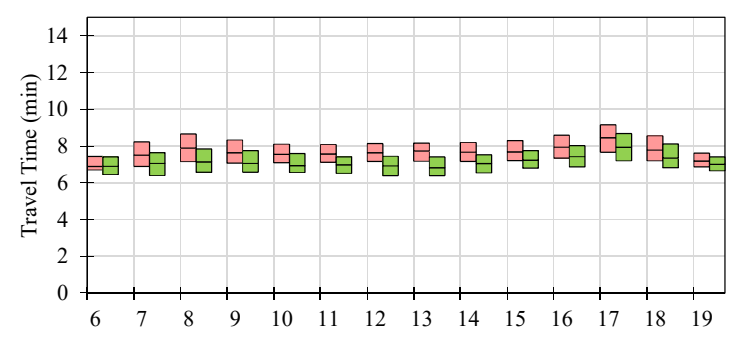

d) Corridor A2, Westbound
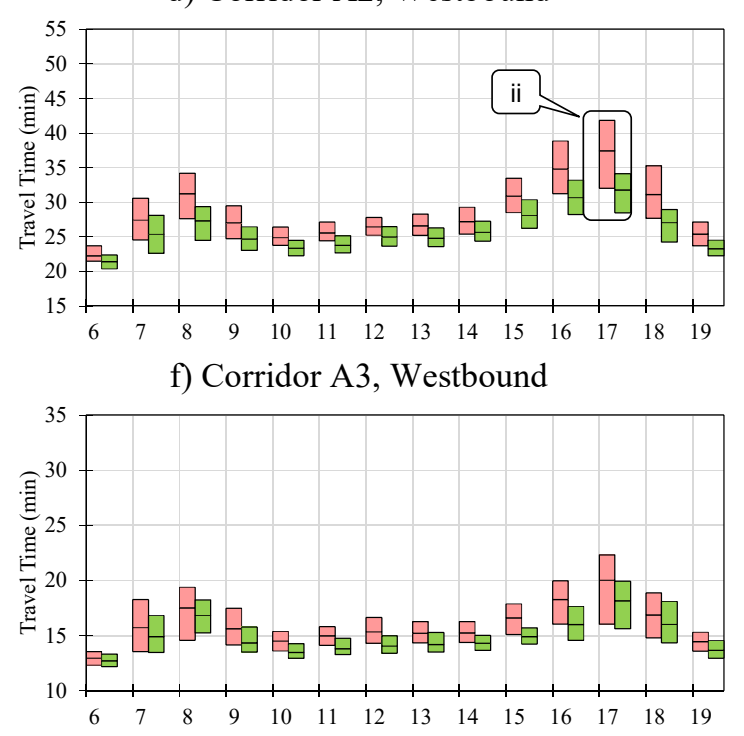

h) Corridor A4, Southbound

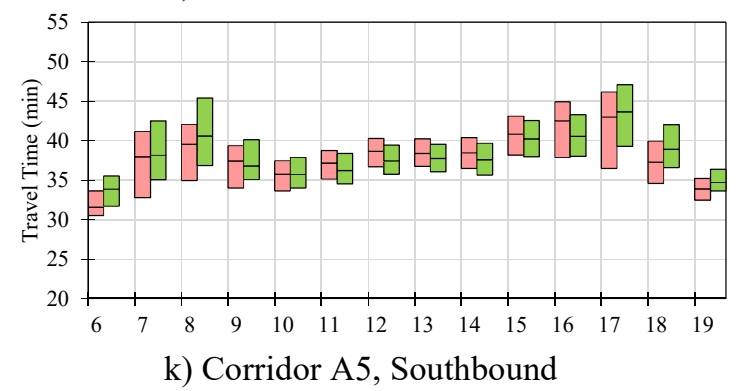

Figure 7. Weekday Median Travel Times and Interquartile Ranges by Hour 


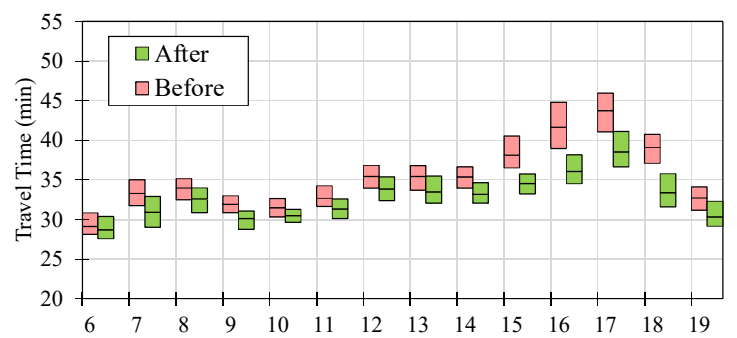

a) Corridor A1, Eastbound

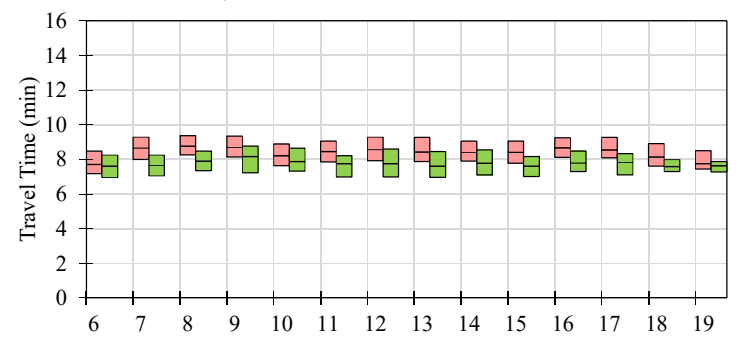

c) Corridor A2, Eastbound

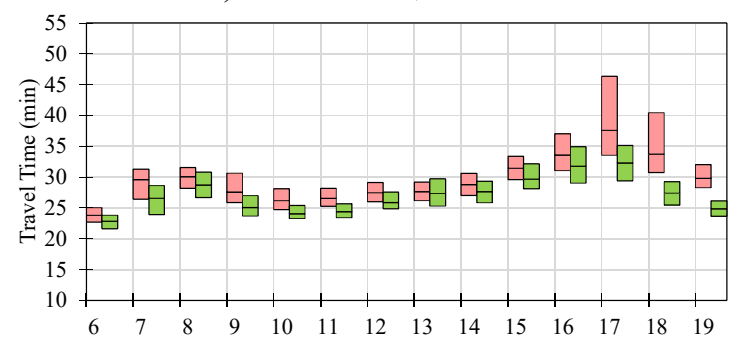

e) Corridor A3, Eastbound

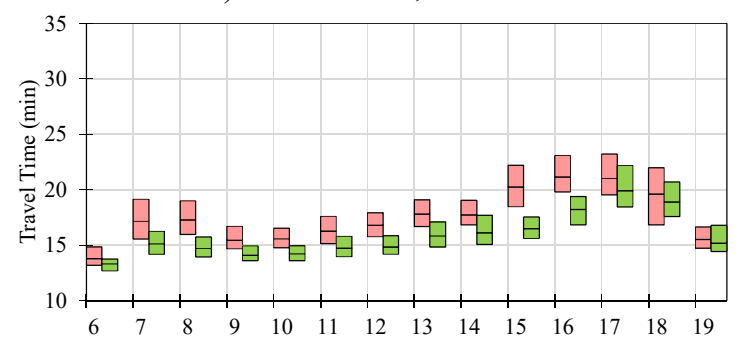

g) Corridor A4, Northbound

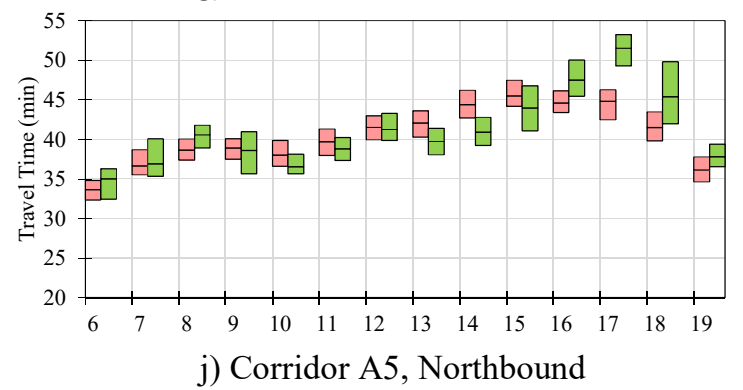

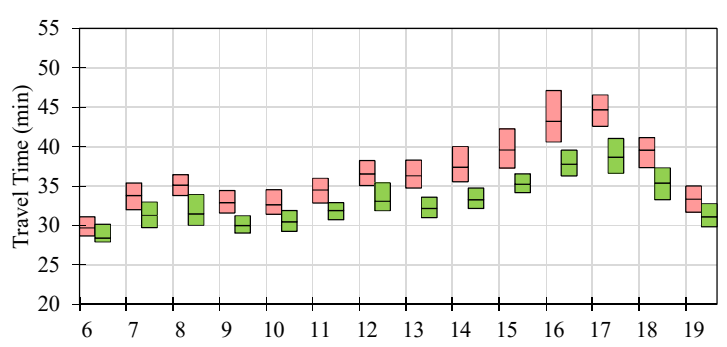

b) Corridor A1, Westbound

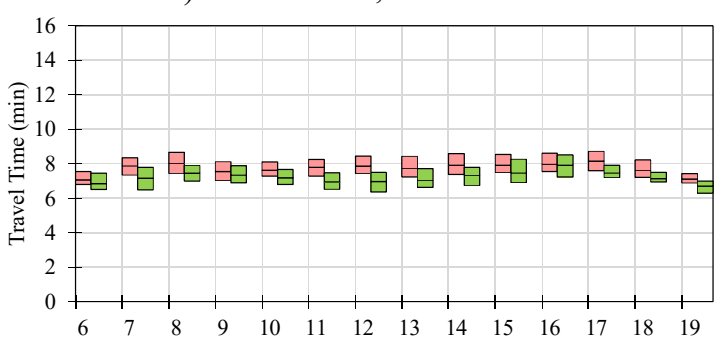

d) Corridor A2, Westbound
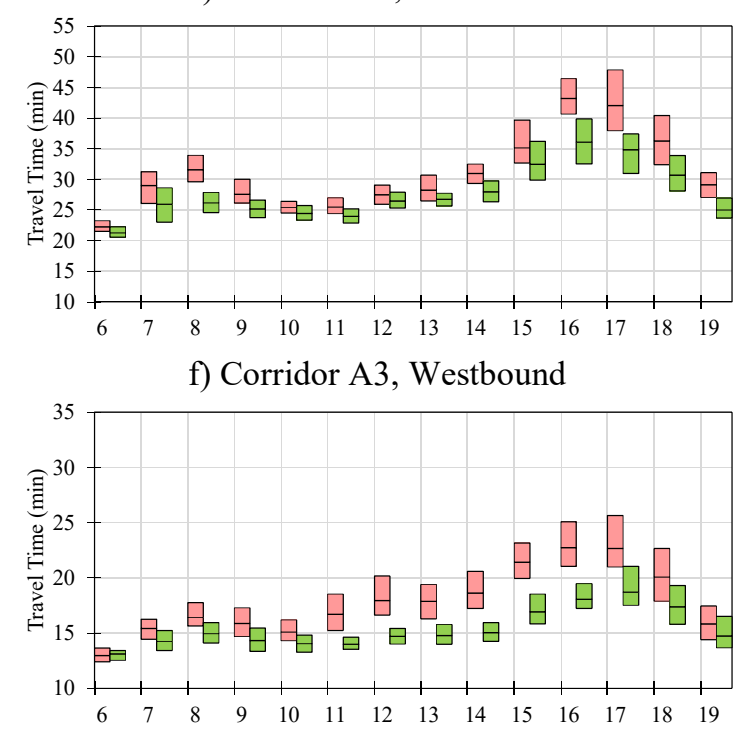

h) Corridor A4, Southbound

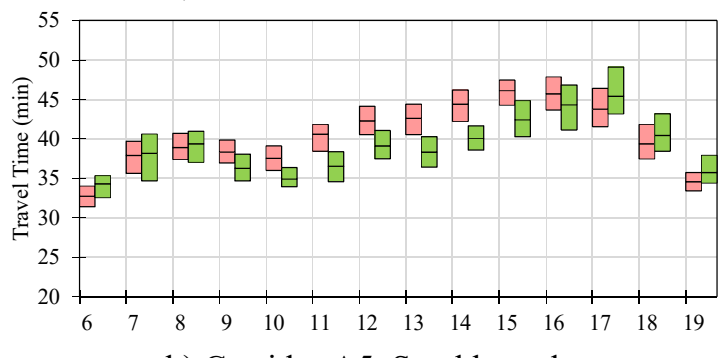

h) Corridor A5, Southbound

Figure 8. Weekend Median \& IQR by Hour 


\section{USER BENEFIT CALCULATION}

The calculation of user benefits is achieved through the use of existing annual average daily traffic (AADT) data provided for the corridors in combination with information found in the 2014 Pennsylvania Traffic Data Report (13) .This report provided data on hourly vehicle and truck traffic percentages. These numbers are determined for 92 study locations across the state. Each of these locations are categorized into 10 traffic pattern groups. The five corridors in this study are defined as "TPG 3, Urban - Other Principle Arterials." Additional user benefit design values were adapted from the 2015 Urban Mobility Scorecard (14), including vehicle occupancy, commercial vehicle operating cost, and average cost of time. The time period selected for the analysis is from 6:00 AM to 8:00 PM.

The hourly volumes are estimated by equation (1)

where,

$$
\operatorname{vol}_{i}=A A D T^{*} k_{i} * d
$$

$$
\begin{aligned}
\mathrm{vol}_{\mathrm{i}} & =\text { estimated volume for hour } \mathrm{i} \\
\mathrm{AADT} & =\text { annual average daily traffic } \\
\mathrm{k}_{\mathrm{i}} & =\text { hourly vehicle percentages from }(13) \\
\mathrm{d} & =\text { directional distribution (assumed to be } 0.5)
\end{aligned}
$$

The difference in travel time for each hour, before and after the adaptive signal deployment is calculated using the following equation

$$
\Delta T T_{i}=T T_{\text {before }, i}-T T_{a f t e r, i}
$$

where,

$\mathrm{TT}_{\text {before }, \mathrm{i}}=$ median travel time during the before period for hour $\mathrm{i}$

$\mathrm{TT}_{\mathrm{after}, \mathrm{i}}=$ median travel time during the after period for hour $\mathrm{i}$

The user benefit for trucks during each hour is then calculated using equation (3)

where,

$$
\text { user }_{\text {truck }, i}=\operatorname{vol}_{i} * \Delta T T_{i} * \% T_{i} * P P V_{t} * V O T_{t}
$$

$\% \mathrm{~T}_{\mathrm{i}}=$ percentage of truck traffic for hour i, from (13)

$\mathrm{PPV}_{\mathrm{t}}=$ number of passengers for commercial vehicles (1 for trucks)

$\mathrm{VOT}_{\mathrm{t}}=$ time value of money for commercial vehicles, $\$ 94.04 /$ vehicle-hr from (14)

Similarly, the user benefits for passenger cars were computed using equation (4)

$$
\operatorname{user}_{\text {car }, i}=\operatorname{vol}_{i} * \Delta T T_{i} * \% C_{i} * P P V_{c} * V O T_{c}
$$

where,

$\% \mathrm{C}_{\mathrm{i}}=$ percentage of car traffic for hour $\mathrm{i}$, assumed as $\left(1-\% T_{i}\right)$

$\mathrm{PPV}_{\mathrm{c}}=$ number of passengers for commercial vehicles, 1.25 for cars from (14)

$\mathrm{VOT}_{\mathrm{c}}=$ time value of money for passenger cars, $\$ 17.67 /$ person-hr from (14)

The hourly user costs for passenger cars and commercial trucks in both the directions are aggregated to compute the daily user cost for each corridor. The annual user costs are then computed by using weekly and yearly multipliers. Analysis is carried out separately for weekdays and weekends, and the results are shown in Figure 9. 


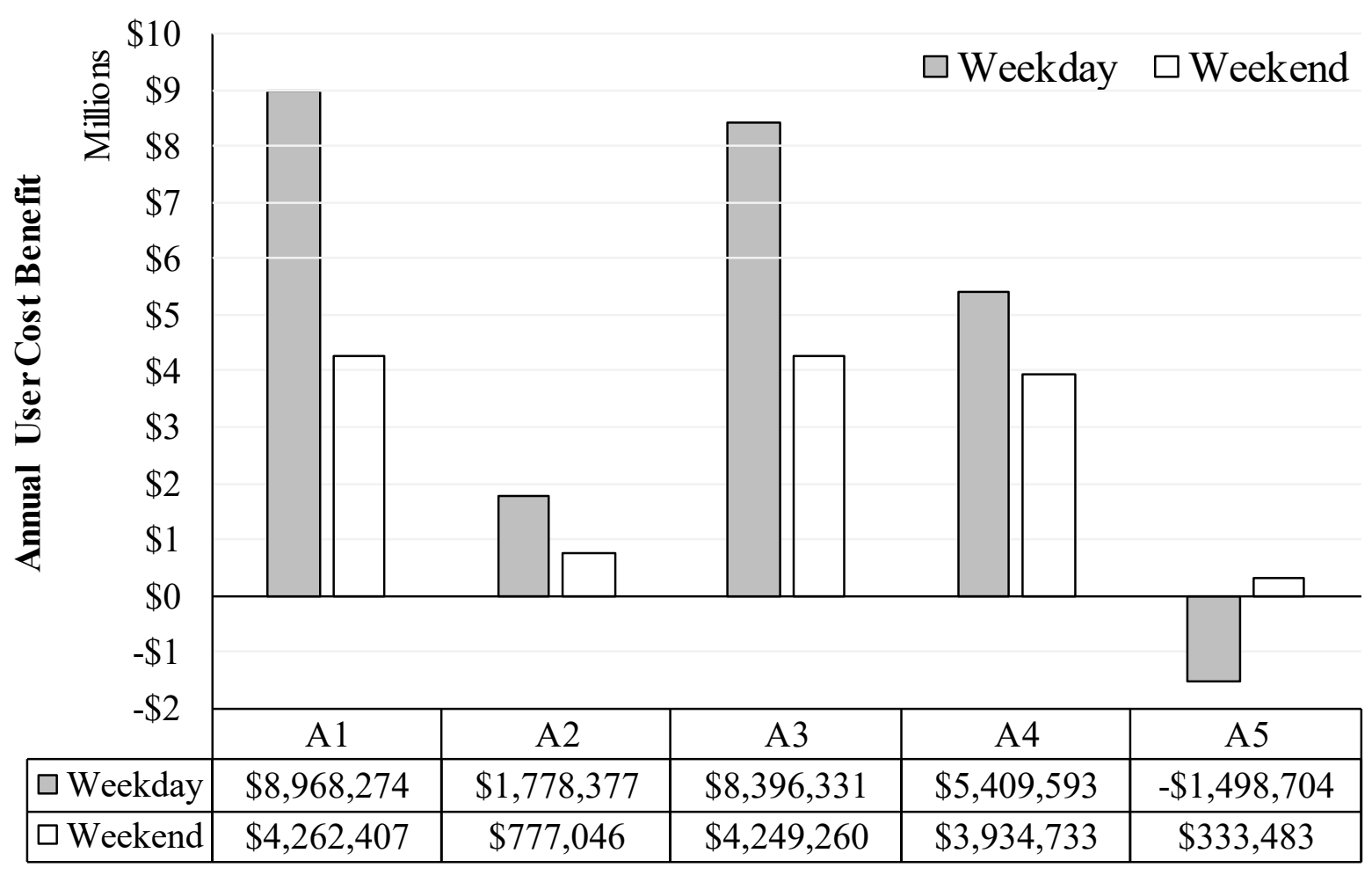

Figure 9. Summary of Annual User Cost Benefits for the 5 Corridors

In addition to the user costs, changes in carbon dioxide $\left(\mathrm{CO}_{2}\right)$ emissions are computed using the method adopted by (15). Using conversion factors from the Argonne National Laboratory, a passenger car is expected to consume $0.87 \mathrm{gal}$ of gasoline per hour. This number is conservatively used to determine the fuel consumption, as given by equation (5)

$$
\text { fuel }=\Delta T T^{*} \text { vol } * \frac{0.87 \mathrm{gal}}{\text { hour }}
$$

Equation (6) computes the $\mathrm{CO}_{2}$ emissions in tons. According to the U.S. Environmental Protection Agency, the amount of $\mathrm{CO}_{2}$ emitted when a gallon of gasoline burns is approximately $19.6 \mathrm{lb} / \mathrm{gal}$ (16).

$$
\mathrm{CO}_{2 \text { emissions }}=\text { fuel } * \frac{19.6 \mathrm{lb}}{\text { gal }} * \frac{1 \text { ton }}{2,000 \mathrm{lb}}
$$

The USEPA also estimates the social cost of $\mathrm{CO}_{2}$ as $\$ 36 /$ ton (17) and the cost of $\mathrm{CO}_{2}$ is determined using equation (7).

$$
C C=C O_{2 \text { emissions }} * \frac{\$ 36}{\text { ton }}
$$

The weekday and weekend savings as well as emissions for $\mathrm{CO}_{2}$ is given in Table 2 . 
Table 2. Summary of Annual CO2 Emission Reductions for the Adaptive Signals

\begin{tabular}{|c|c|c|c|c|}
\hline \multirow{2}{*}{ Corridor } & \multicolumn{2}{|c|}{ Weekday $\mathbf{C O}_{2}$ Savings } & \multicolumn{2}{c|}{ Weekend $\mathbf{C O}_{2}$ Savings } \\
\cline { 2 - 5 } & Tons & Dollars & Tons & Dollars \\
\hline A1 & 2878.45 & $\$ 103,624$ & 1372.94 & $\$ 49,426$ \\
\hline A2 & 570.09 & $\$ 20,523$ & 249.48 & $\$ 8,981$ \\
\hline A3 & 2711.70 & $\$ 97,621$ & 1378.65 & $\$ 49,632$ \\
\hline A4 & 1735.24 & $\$ 62,469$ & 1258.45 & $\$ 45,304$ \\
\hline A5 & -500.38 & $\mathbf{- \$ 1 8 , 0 1 4}$ & 93.01 & $\$ 3,348$ \\
\hline Total & $\mathbf{7 3 9 5 . 1 1}$ & $\mathbf{\$ 2 6 6 , 2 2 4}$ & $\mathbf{4 3 5 2 . 5 4}$ & $\$ \mathbf{1 5 6 , 6 9 1}$ \\
\hline
\end{tabular}

As shown, all corridors saw improvements in annual user benefits and $\mathrm{CO}_{2}$ savings, except corridor A5. Altogether, these corridors accounted for $\$ 36.6$ million in annual user benefits and $\$ 422,915$ in $\mathrm{CO}_{2}$ yearly savings. The greatest improvements are broken down by weekend totals of $\$ 13.5$ million and $\$ 156,691$, compared to weekday totals of $\$ 23.05$ million and $\$ 266,224$. Of these five corridors, A1 and A3 had the highest user benefit savings and $\mathrm{CO}_{2}$ savings, totaling $\$ 25.8$ million and $\$ 300,000$. As mentioned previously, corridor A2 had reliable travel times before the adaptive installation, and, therefore, had the least amount of travel time impact and cost savings. Corridor A4 had similar weekend improvements as A1 and $\mathrm{A} 3$ but was not as effective for weekdays. Negative user benefit and $\mathrm{CO}_{2}$ savings for corridor $\mathrm{A} 5$ can be attributed to the increased travel times displayed in Figure 7 and Figure 8.

\section{INTERACTIVE WEB APPLICATION}

The results presented in this paper are based upon the interactive Travel Time web application being developed for Pennsylvania Department of Transportation to easily compare travel times for any corridor in the database. A screenshot of the application screens are shown in Figure 10a. Corridors can be selected from the interactive map or using the dropdown menu. A selected corridor will become highlighted on the map to verify the selection choice. The web application also allows for the user to customize parameters, including date ranges, day of week ranges, hour ranges, and axes bounds. The date range selection tab includes before and after calendars to choose the desired ranges. The day of week tab allows for the toggling of any day of week to be included in the analysis. Also, within the day of week tab there are switches to automatically toggle to weekends or weekdays only. In the hours tab users can select from a variety of different hours options. These options include 24 hour, hourly, rush hour splits, and finally a custom hour range slider. Finally, the Axes tab allows for customization of the x-axis graphs that are produced

After the user has set all of their customization choices, simply click on the 'Generate Graphs' button to produce results. One column of graphs will be produced for each direction of travel associated with that corridor. In addition, each column will contain one graph for each hour range chosen. Each graph will contain a red line to represent the before date range, and a green line to represent the after range. On the $\mathrm{x}$ axis is the travel time in minutes. Improvements are represented by a leftward shift of travel time in the before line to the after line. The database functions and procedures of this web app was used to produce the travel time graphs seen in this study. 


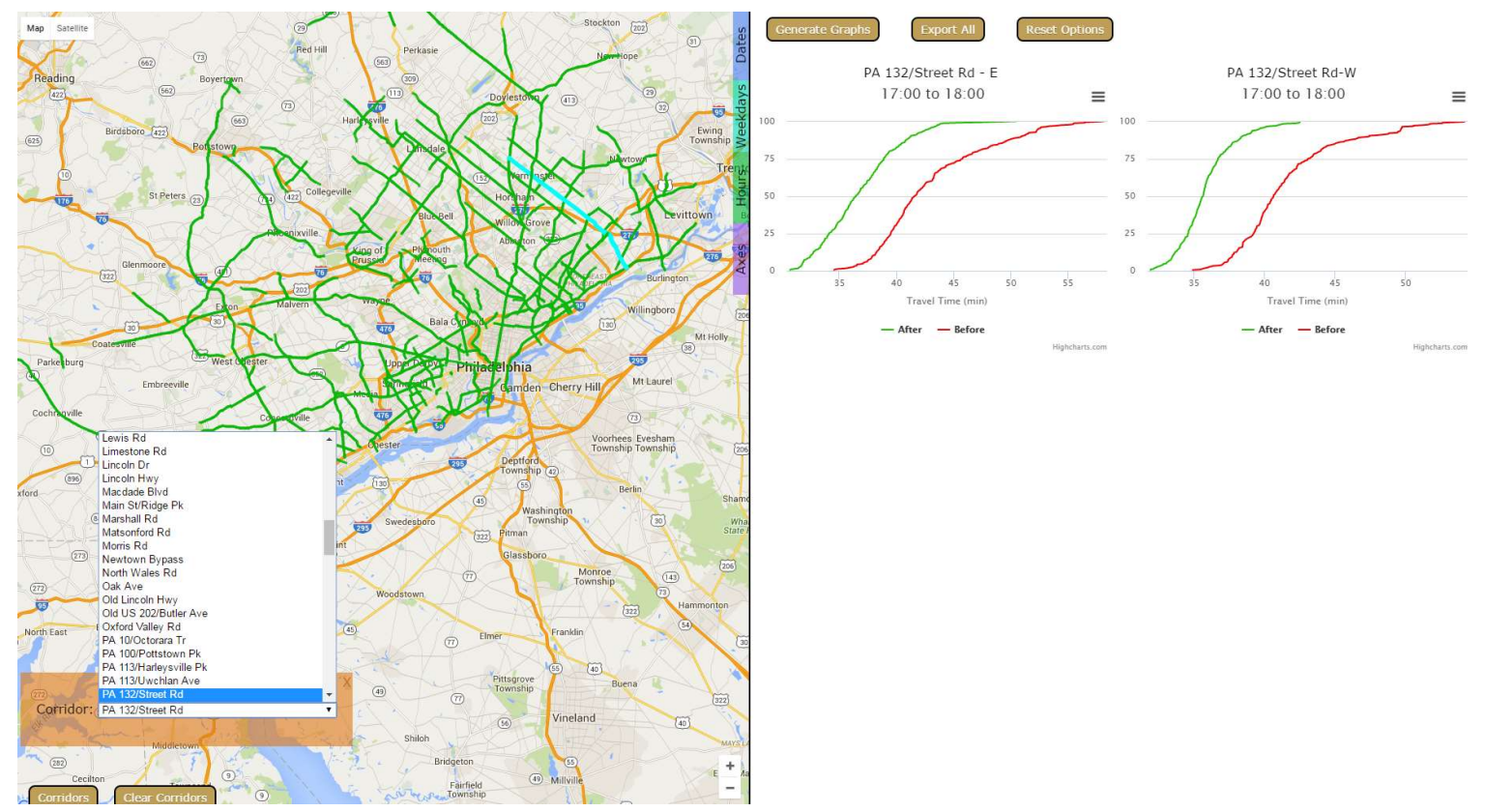

a) Tool for analyzing before/after changes in travel time and quantifying benefits

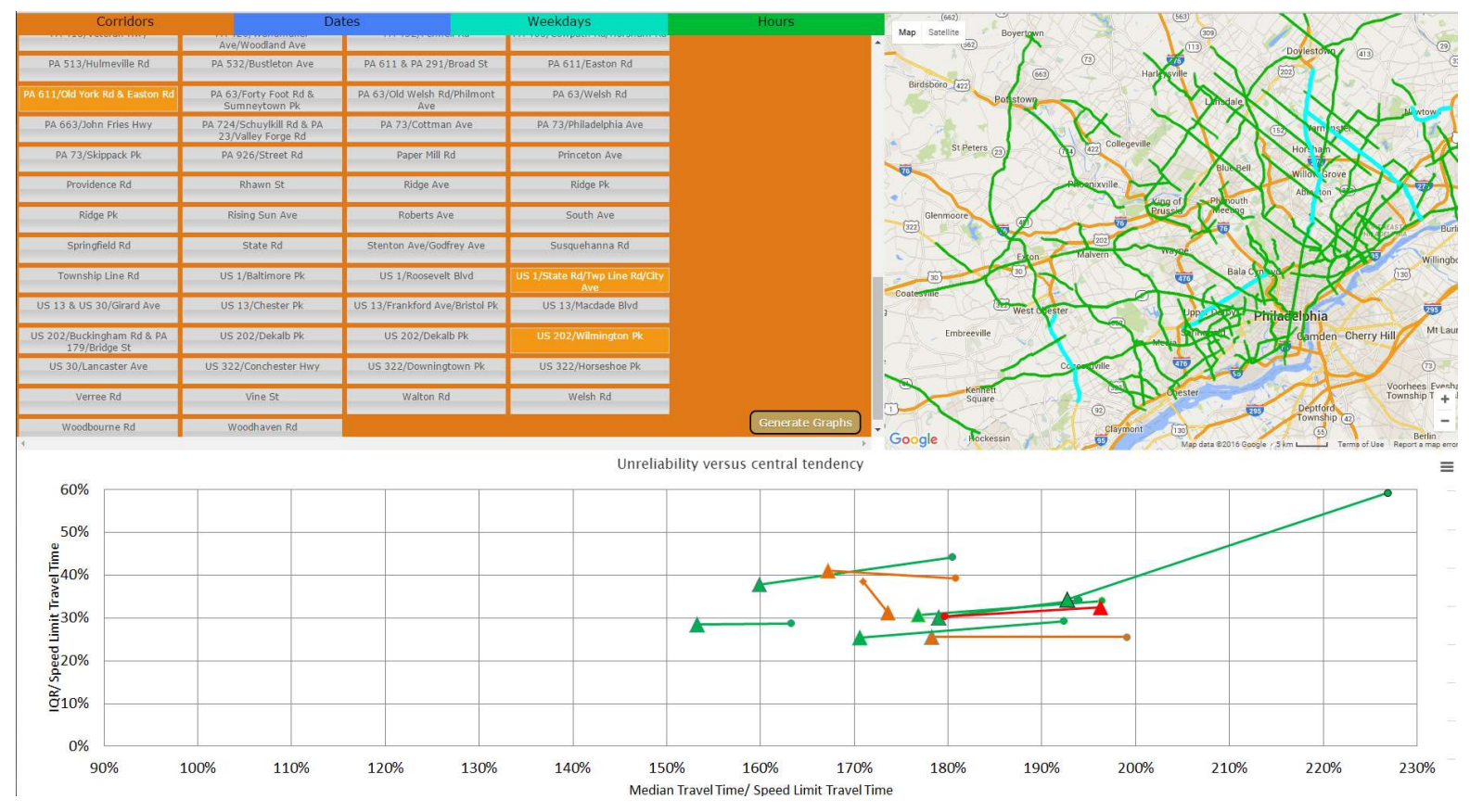

b) Tool for identifying corridors with high relative travel times or poor travel time reliability

Figure 10. Travel Time Web Application Tool 
The Trends application is also being developed (Figure 10b). This web application shares many of the same customization options as the Travel Time application. However, this application is oriented toward network level assessment of multiple corridors to identify corridors with high relative travel times and high degree of travel time unreliability.

\section{CONCLUSIONS}

This study examined travel times on five arterial routes surrounding Philadelphia. As part of a larger project sponsored by PennDOT, these arterials were identified as high-volume signalized corridors. A method was presented in which one-hour intervals were analyzed throughout the week. Corridor evaluations from 6:00 AM to 8:00 PM were based on median travel times and comparisons of IQR. Six-week averages of travel times were used before and after the adaptive installation for a consistent period of comparison. Changes in travel times were used to calculate user benefit and $\mathrm{CO}_{2}$ savings.

Overall, the implementation of adaptive signals provided great improvement to the travel times and reliability of the corridors. Collectively, the five corridors produced an annual user benefit of \$36.6 million and a $\mathrm{CO}_{2}$ savings of $\$ 422,915$. A majority of these savings, over $66 \%$, can be attributed to corridors $\mathrm{A} 1$ and A3. Additionally, over half the savings were due to weekend improvements. Corridors A2 and A5 were two corridors that did not see large improvements with the implementation of adaptive signals. Corridor A2 saw nominal performance improvement likely attributed to previously short and reliable travel times. On the other hand, A5 experienced longer travel times and decreased reliability. Further studies on this corridor and other implementations and evaluations are forthcoming.

Longer term, the authors believe tools similar to those described in this paper should be integrated into modern traffic signal central systems to perform outcome assessment. These dashboards would provide agencies with an integrated environment for identifying candidate corridors for signal coordination and retiming projects and as outcome assessment tools to quantify user benefit dollars once those projects are completed.

Lastly, this paper focused on a methodology for assessing travel times for the mainline movements. However, some retiming projects may sacrifice green time allocated to minor movements for better arterial progression. A comprehensive corridor study should also include a movement-by-movement tabulation of split failures (18) for each time-of-day pattern to ensure adequate green time is provided for those minor movements as well.

\section{ACKNOWLEDGMENTS}

This work was supported in part by the Pennsylvania Department of Transportation. The connected vehicle data was provided by INRIX, Inc. The contents of this paper reflect the views of the authors, who are responsible for the facts and the accuracy of the data presented herein, and do not necessarily reflect the official views or policies of the sponsoring organizations. These contents do not constitute a standard, specification, or regulation. 


\section{REFERENCES}

1. Quiroga, C.A. and D. Bullock. "Measuring Control Delay at Signalized Intersections." Journal of Transportation Engineering, 125, 1999, 271-280.

2. Day, C.M., R.J. Haseman, H. Premachandra, T.M. Brennan, J.S. Wasson, J.R. Sturdevant, and D.M. Bullock. "Evaluation of Arterial Signal Coordination: Methodologies for Visualizing High-Resolution Event Data and Measuring Travel Time." Transportation Research Record No. 2192, 2010, 37-49.

3. Quayle, S.M., P. Koonce, D. Depencier, and D.M. Bullock. "Arterial Performance Measures with Media Access Control Readers: Portland, Oregon Pilot Study." Transportation Research Record No. 2192, 2010, 185-193.

4. Wang, Y., B.N. Araghi, Y. Malinovskiy, J. Corey, and T. Cheng. Error Assessment for Emerging Traffic Data Collection Devices. Report WA-RD 810.1, Pacific Northwest Transportation Consortium, University of Washington, 2014.

5. Hu, J., M.D. Fontaine, and J. Ma. "Quality of Private Sector Travel-Time Data on Arterials." Journal of Transportation Engineering, 142, 2016, 04016010.

6. Sharifi, E., S.E. Young, S. Eshragh, M. Hamedi, R.M. Juster, and K. Kaushik. "Quality Assessment of Outsourced Probe Data on Signalized Arterials: Nine Case Studies in Mid-Atlantic Region." Presented at Transportation Research Board Annual Meeting, 2016.

7. Day, C.M., S.M. Remias, H. Li, M.M. Mekker, M.L. McNamara, E.D. Cox, and D.M. Bullock. "Performance Ranking of Arterial Corridors Using Travel Time and Travel Time Reliability Metrics." Transportation Research Record No. 2487, 2015, 44-54.

8. Campbell, R. and Skabardonis, A., Field Testing the Effectiveness of Adaptive Traffic Control for Arterial Signal Management. Report UCB-ITS-PRR-2014-3. Institute of Transportation Studies, University of California, Berkeley, 2014.

9. Hu, J., M.D. Fontaine, B.B. Park, and J. Ma. "Field Evaluations of an Adaptive Traffic Signal—Using Private-Sector Probe Data." Journal of Transportation Engineering, 141, 2015, 04015033.

10. Pennsylvania Department of Transportation. "Green Light - Go: Pennsylvania's Municipal Signal Partnership Program." Available online at http://www.dot.state.pa.us/public/Bureaus/BOMO/Portal/GLG_INFO.pdf

11. List, G.F. et al. Establishing Monitoring Programs for Travel Time Reliability. Report S2-L02-RR-1, SHRP 2, Transportation Research Board, 2014.

12. Remias, S.M., A.M. Hainen, C.M. Day, T.M. Brennan, H. Li, E. Rivera-Hernandez, J.R. Sturdevant, S.E. Young, and D.M. Bullock. "Performance Characterization of Arterial Traffic Flow Using Probe Vehicle Data." Transportation Research Record No. 2380, 2013, 10-21.

13. Pennsylvania Department of Transportation. "2014 Pennsylvania Traffic Data." Available online at http://www.dot7.state.pa.us/BPR_pdf_files/Documents/Traffic/Traffic_Information/Annual_Report/2014/2 014_Traffic_Information_Report.pdf

14. Schrank, D., Eisele, B., \& Lomax, T. 2015 Urban Mobility Scorecard. Texas A\&M Transportation Institute, 2015.

15. Day, C.M., T.M. Brennan, A.M. Hainen, Remias, S.M, H. Premachandra, J.R. Sturdevant, Richards, G., J.S. Wasson and D.M. Bullock. "Reliability, Flexibility, and Environmental Impact of Alternative Objective functions for Arterial Offset Optimization." Transportation Research Record No. 2259, 2011, 822.

16. U.S. Environmental Protection Agency. Greenhouse Gas Equivalencies Calculator. May 2016. https://www.epa.gov/energy/greenhouse-gas-equivalencies-calculator. Accessed July 18, 2016. 
17. U.S. Environmental Protection Agency. EPA Fact Sheet Social Cost of Carbon. Dec. 2015. https://www3.epa.gov/climatechange/Downloads/EPAactivities/social-cost-carbon.pdf. Accessed July 18,= 2016.

18. Freije, Richard, S., A.M Hainen, A.L. Stevens, H. Li, W.B. Smith, H.T. Summers, C.M. Day, J.R.= Sturdevant and D.M. Bullock, "Graphical Performance Measures for Practitioners to Triage Split Failure= Trouble Calls," Transportation Research Record: Journal of the Transportation Research Board, No. 2439,= Transportation Research Board of the National Academies, Washington, D.C., pp. 27-40, October 2014.= DOI: $10.3141 / 2439-03$. 